\title{
Granuloma reparativo de células gigantes. Revisión bibliográfica y presentación de un caso
}

\author{
F. Corella Montoya ${ }^{(1)}$, M. C. Pulido García ${ }^{(2)}$, \\ G. Pacheco Martins Ferreira ${ }^{(3)}$, A. Luch Homedes ${ }^{(4)}$ \\ ${ }^{(1)}$ MÉdico Residente de COT. Hospital General Universitario GREGorio Marañón. MadRid \\ ${ }^{(2)}$ MÉdico Residente de COT. Hospital de la SANTA CREU I SANT PaU. UAB, Barcelona \\ ${ }^{(3)}$ Médico. Cirujano de la Sociedad Brasileña de Cirugía de Mano. Belo Horizonte. Brasil \\ ${ }^{(4)}$ Médico. Cirujano Ortopédico y TRaumatólogo del Instituto Kaplan. Centro de Cirugía de \\ LA MANO Y EXTREMIDAD SUPERIOR. BARCELONA
}

Correspondencia:

Dr. Fernando Corella Montoya

Servicio de Cirugía Ortopédica y Traumatología. H. G. U. Gregorio Marañón

C/ Doctor Esquerdo, no 42

28007 Madrid.

Tels.: 915868426

E-mail: fernando.corella@gmail.com

\begin{abstract}
Presentamos el caso clínico de un varón de doce años con un granuloma reparativo de células gigantes (GRCG) en el metacarpiano del dedo medio de la mano, diagnosticado inicialmente como quiste óseo aneurismático. Se realiza una revisión bibliográfica del GRCG, comentando sus características clínicas, radiológicas y anatomopatológicas; y también, su diagnóstico diferencial con el tumor de células gigantes óseo, el quiste óseo aneurismático y el tumor pardo del hiperparatiroidismo.
\end{abstract}

Palabras clave: Granuloma reparativo de células gigantes, tumor óseo, metacarpiano, tumor de células gigantes óseo, quiste óseo aneurismático, tumor pardo hiperparatiroidismo.
A giant cell reparative granuloma in the middle finger metacarpal of a twelve year boy was treated after the recurrence of a lesion initially diagnosed as an aneurismal bone cyst.

Differential diagnosis between bone giant cell tumors, aneurismal bone tumors and brown tumors seen in hyperparathyroidism, based on clinical, radiographic and histological signs, is discussed. A comprehensive literature review of giant cell reparative granulomas is also presented.

Key words: Giant cell reparative granuloma, bone tumor, metacarpal, giant cell tumor, aneurysmal bone cyst, hyperparathyroidism brown tumor

Rev. Iberam. Cir. Mano - Vol. 35 - Núm. 1 Mayo 2007 (52-56)

\section{INTRODUCCIÓN}

El granuloma reparativo de células gigantes (GRCG), es una lesión benigna e infrecuente, que suele afectar a huesos del macizo facial.

Puede confundirse con otros tumores, principalmente el quiste óseo aneurismático (QOA), el tumor pardo del hiperparatiroidismo (TPH) y el tumor de células gigantes óseo (TCGO). Es muy importante hacer el diagnóstico diferencial correctamente por su diferente evolución y tratamiento.

Presentamos un caso de un GRCG, con el diagnóstico inicial de QOA, que recidivó y precisó una resección amplia e injerto corticoesponjoso. 


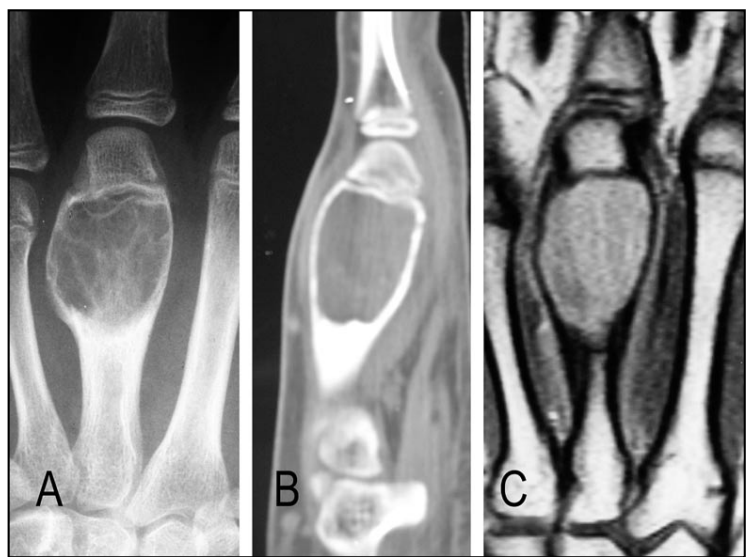

Figura 1: A.- Lesión insuflativa en el tercio distal del metacarpiano del dedo medio, que adelgaza la cortical. No existe reacción perióstica, ni afectación de partes blandas. B.- TAC con estructura heterogénea en su interior, sin ninguna matriz característica y con un nivel líquido-líquido. La fisis hace de barrera distal de la lesión. C.- RM en T1 se observa una imagen hipointensa, apreciándose en la secuencia de T2 una hiperseñal heterogénea con compartimentalización de la lesión. Existen niveles líquido-líquido dentro de la tumoración.

\section{CASO CLÍNICO}

Varón de 12 años, con engrosamiento y dolor en el dorso de la mano izquierda de dos meses de evolución. Se realizó un estudio de imagen mediante radiografía simple, TAC y RM (Figura 1A, B y C). Este estudio sugería como diagnóstico más probable el de QOA.

Se le practicó un curetaje y relleno con autoinjerto de peroné. El diagnóstico anatomopatológico fue de QOA.

La clínica persistió tras la cirugía y se observó la reabsorción del injerto y el aumento de

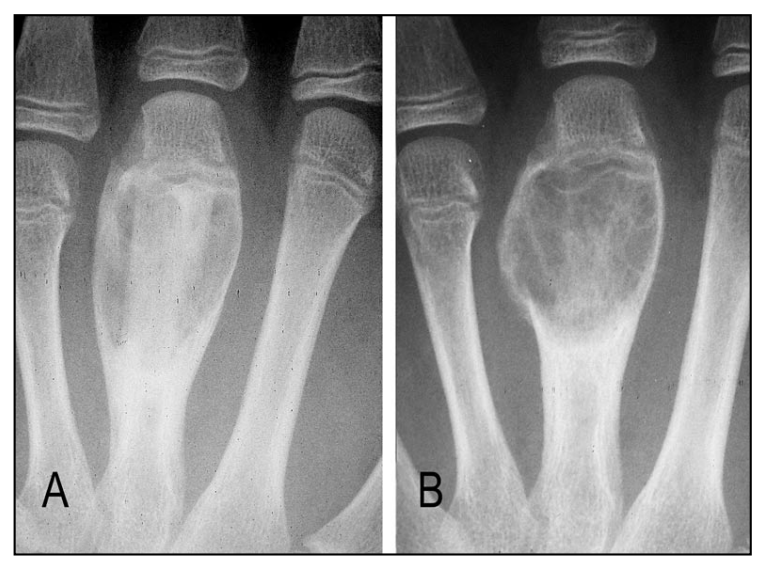

Figura 2: Radiografía de la recidiva y reabsorción del injerto tras la primera cirugía.

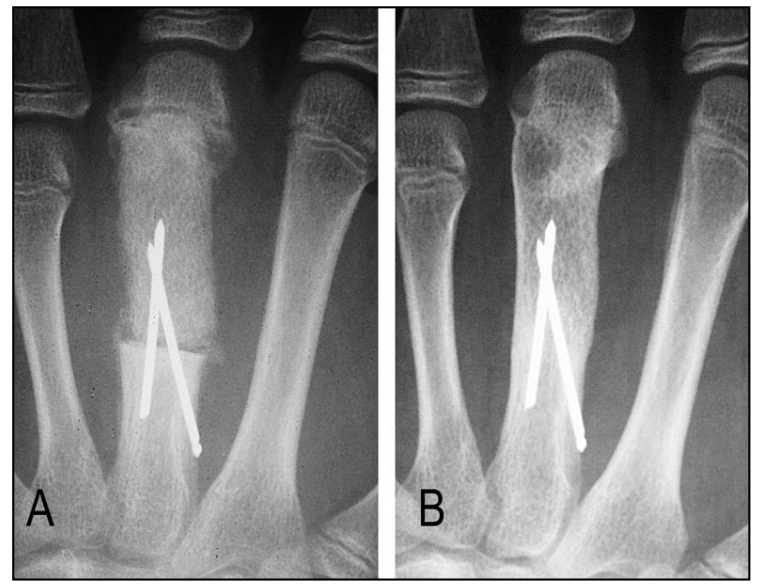

Figura 3: A.- Resultado inmediato tras la segunda cirugía. B.- Recidiva a los 4 meses.

tamaño de la lesión (Figura 2). A los seis meses después de la intervención, nos fue remitido para el tratamiento de la recidiva.

En la nueva intervención quirúrgica se practicó la resección subperióstica de la lesión y la colocación de un autoinjerto cortico-esponjoso intercalar, obtenido de la metáfisis distal de la tibia. El injerto óseo fue $3 \mathrm{~mm}$. más largo que el segmento resecado, para compensar el hipocrecimiento fisario. Se estabilizó, con dos agujas de Kirschner (Figura 3A).

La descripción anatomopatológica fue de lesión con espacios quísticos aneurismáticos. Estroma fibroso y trabéculas de hueso plexiforme con osteoide no laminado y reacción osteoclástica. Células gigantes multinucleadas, de 5 a 25 núcleos, tamaño intermedio, que tienden a agregarse en zonas de extravasación de eritrocitos.

Se diagnosticó de Granuloma Reparativo de Células Gigantes, con formación de QOA.

La evolución fue satisfactoria hasta los 4 meses, momento en que se observa una pequeña recidiva (Figura 3B). Se trató mediante curetaje y relleno con injerto óseo esponjoso.

Los controles radiológicos y clínicos posteriores a esta tercera cirugía han sido satisfactorios, con una remodelación completa del metacarpiano y una movilidad normal (Figuras 4 y 5).

\section{DISCUSIÓN}

El GRCG, es una lesión reactiva, benigna e infrecuente, que suele afectar al macizo facial. 


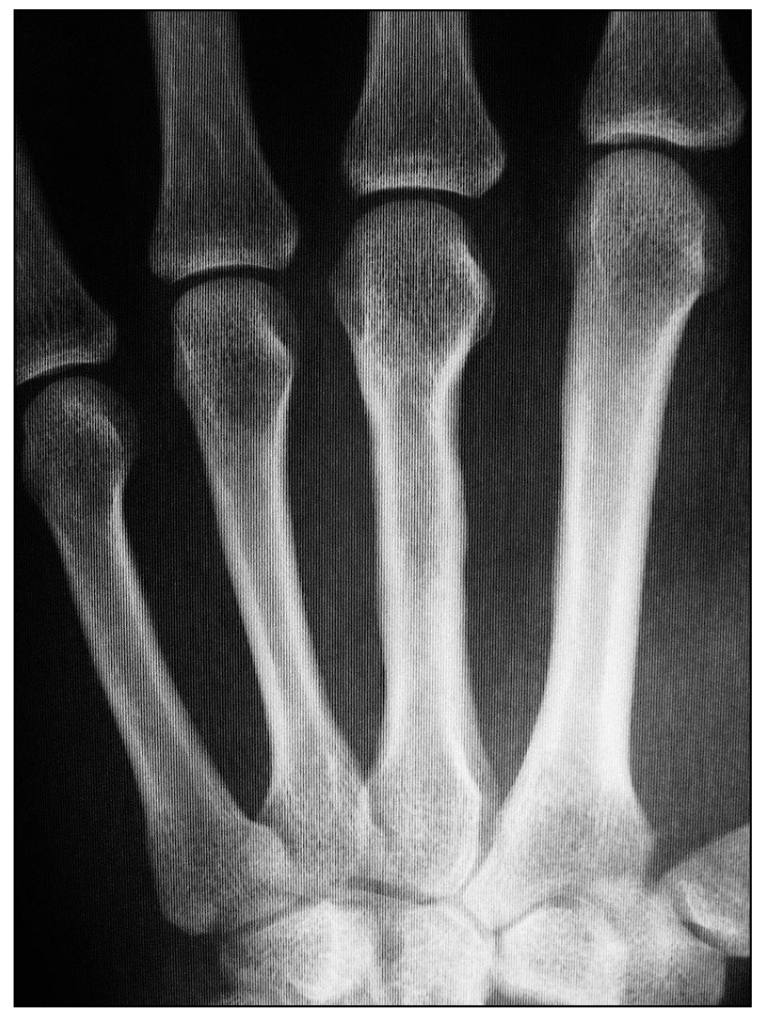

Figura 4: Radiografía con remodelación completa del metacarpiano en el momento actual.

Descrito, en primer lugar por Jaffe ${ }^{1}$ en la mandíbula, diversos autores ${ }^{2-5}$ presentaron casos similares en otras localizaciones, hasta que Lorenzo y Dorfman en $1980^{6}$ dieron el nombre de GRCG.

El GRCG suele aparecer entre la segunda y tercera décadas de la vida, con el doble de incidencia en mujeres. Los síntomas más comunes son el dolor y el engrosamiento. La duración de los síntomas previa al diagnóstico varía de las 4 semanas a los 10 años $^{3,4,6-10}$. En nuestro caso se tardó 2 meses en realizar el diagnóstico.

Radiográficamente, se caracteriza por ser una lesión metafisaria expansiva y osteolítica. La lesión suele estar bien delimitada, con la cortical adelgazada, pero muy excepcionalmente ro$\mathrm{ta}^{8}$.

Microscópicamente se caracteriza por una distribución irregular de células gigantes alrededor de focos hemorrágicos. Estas células son pequeñas, de forma irregular y con pocos núcleos. El estroma presenta una moderada o alta densidad celular, abundante fibrosis y un infiltrado linfocítico. Tiene pequeños sinusoides

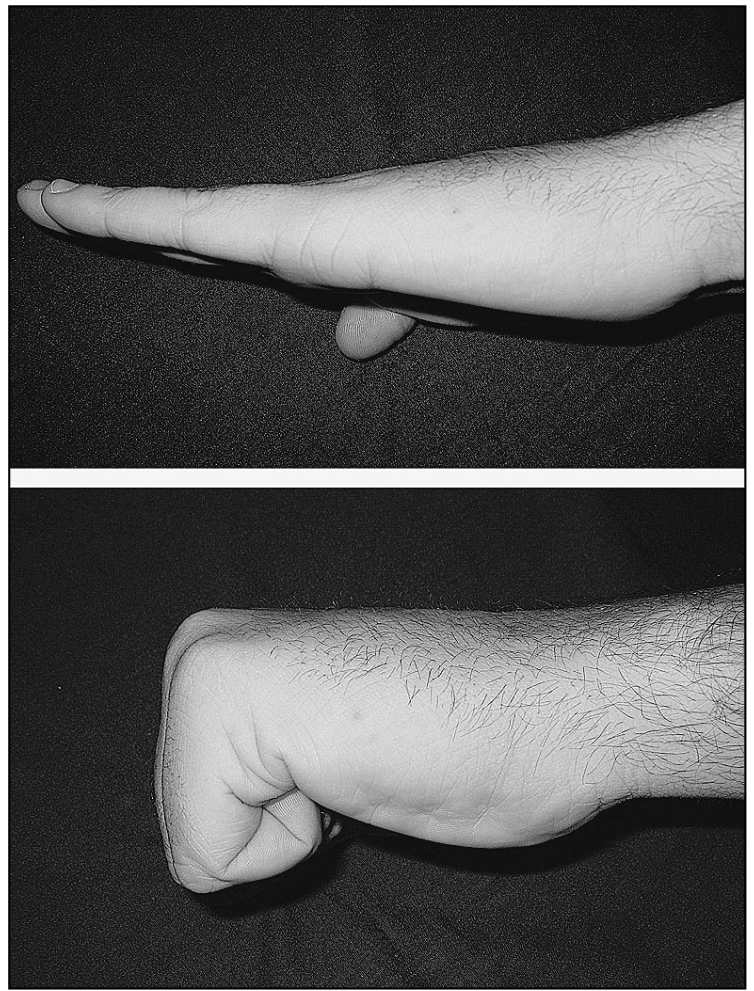

Figura 5: Resultado funcional.

rellenos de sangre y quistes vacíos con zonas reactivas de formación de hueso alrededor de los lagos vasculares ${ }^{1,7,10-13}$.

\section{DIAGNÓSTICO DIFERENCIAL}

El diagnóstico diferencial se debe realizar con el TPH, con el QOA y con el TCGO, ya que clínica y radiológicamente son similares.

En el TPH aparece una osteopenia generalizada, lesiones osteolíticas en distintos huesos y sobre todo alteraciones analíticas en el calcio, fósforo y $\mathrm{PTH}^{10,12,14}$.

Las principales diferencias con el TCGO son su edad más tardía, su afectación epifisaria y su mayor agresividad radiológica. Histológicamente, las células gigantes son más numerosas, más redondeadas, con núcleos más grandes y numerosos. El estroma tiene un menor infiltrado linfocítico y raramente hay una producción ósea reactiva ${ }^{7,10,11,13,15-16 .}$

Es muy importante su diagnóstico diferencial ya que el GCRG se considera un proceso óseo reparativo ${ }^{14,17}$, mientras que el TCGO puede malignizar y ocasionar metástasis ${ }^{18-19}$. 
El QOA presenta más frecuentemente una rotura de la cortical y un mayor número de niveles de líquido ${ }^{13}$. Histológicamente los quistes vasculares son de mayor tamaño.

Las similitudes son tan marcadas, que existe una variedad de QOA descrita por Sanerkin ${ }^{20}$ denominada variación "sólida" del QOA ${ }^{21-22}$, que comparte la edad, distribución, características radiológicas e histológicas con el GCRG. Muchos autores opinan que se trata del mismo tipo de tumor ${ }^{7}$.

El tratamiento inicial del GCRG es el curetaje más injerto óseo. La tasa de recidiva es del $33 \%{ }^{12}$, sus alternativas terapéuticas son un nuevo curetaje $\mathrm{e}^{10}$, la resección amplia con un injerto óseo intercalar ${ }^{16}$ y la amputación ${ }^{8}$. De toda la bibliografía revisada, la mayoría de autores han tratado las recidivas mediante un nuevo curetaje y posterior relleno.

Nuestro caso es interesante por haberse diagnosticado inicialmente como QOA, obteniéndose el diagnóstico de GRCG tras la segunda cirugía, con el estudio de la pieza de resección completa. En este tejido de resección coexistían áreas de GRCG y de QOA, tal como han descrito otros autores ${ }^{14,23}$. También es de destacar su comportamiento agresivo, con una reabsorción total del injerto de peroné a los 4 meses de la primera intervención. Tras la resección subperióstica completa y el relleno del defecto óseo con un autoinjerto intercalar se han obtenido unos buenos resultados clínicos y funcionales.

\section{BIBLIOGRAFÍA}

1. Jaffe HL. Giant-cell reparative granuloma, traumatic bone cyst, and fibrous (fibro-oseous) dysplasia of the jawbones. Oral Surg Oral Med Oral Pathol, 1953; 6: 159-75.

2. Ackerman LV, Spjut HJ. Tumors of bone and cartilage. En: Spjut HJ, Dorfman HD, Fechner RE, Ackerman LV, (Eds): Atlas of tumor pathology, sect. 2 , fasc 4. Armed forces institute of pathology, Washington, DC, 1962: 295.

3. Jernstrom P, Stark HH. Giant cell reaction of a metacarpal. Am J Clin Pathol, 1971; 55: 77-81.

4. D'Alonzo RT, Pitcock JA, Milford LW. Giant-cell reaction of bone. Report of two cases. J Bone Joint Surg Am, 1972; 54: 1267-71.

5. Schwinn CP. Differential diagnosis of giant cell lesions of bone. IN: Ackerman LV, Spujt HJ, Abell MR (eds): Bones and joints. International academy of pathology monograph. Baltimore: Williams and Wilkins, 1976: 236-99.

6. Lorenzo JC, Dorfman HD. Giantcell reparative granuloma of short tubular bones of the hands and feet. Am J Surg Pathol, 1980; 4: 551-63.
7. Yamaguchi T, Dorfman HD Giant cell reparative granuloma: a comparative clinicopathologic study oflesions in gnathic and extragnathic sites. Int J Surg Pathol, 2001; 9: 189200.

8. Giza E, Stern PJ, Cualing H. Aggressive giant cell reparative granuloma of the metacarpal: a case report. J Hand Surg Am, 1997; 22: 732-6.

9. MacDonald DF, Binhammer PA, Rubenstein JD, Fornasier VL. Giant cell reparative granuloma of the hand: case report and review of giant cell lesions of hands and feet. Can J Surg, 2003; 46: 471-3.

10. Eck HC, Weiner SD. Giant-cell reparative granuloma of the hands and feet. Orthopedics, 2004; 27: 67-70.

11. Merkow RL, Bansal $M$, Inglis AE. Giant cell reparative granuloma in the hand: report of three cases and review of the literature. J Hand Surg Am, 1985; 10: 733-9.

12. Ostrowski ML, Spjut HJ. Lesions of the bones of the hands and feet. Am J Surg Pathol, 1997; 21: 676-90.

13. Hirschl S, Katz A. Giant cell reparative granuloma outside the jaw bone. Diagnostic criteria and review of the literature with the first case described in the temporal bone. Hum Pathol, 1974; 5: 171-81.

14. Ratner V, Dorfman HD. Giantcell reparative granuloma of the hand and foot bones. Clin Orthop Relat Res, 1990; 260: 251-8.

15. Ugwonali O, Eisen RN, Wolfe SW. Repair of a multiply recurrent giant cell reparative granuloma of the hand with wide resection and fibular grafting. J Hand Surg Am, 1999; 24: 1331-6.

16. Wold LE, Dobyns JH, Swee RG, Dahlin DC. Giant cell reaction (giant cell reparative granuloma) of the small bones of the hands ond feet. Am J Surg Pathol, 1986; 10: 491-6.

17. Bertheussen KJ, Holck S, Schiodt T. Giant cell lesion of bone of the hand with particular emphasis on giant cell reparative granuloma. J Hand Surg Am, 1983; 8: 46-9.

18. Dorfman HD, Czernniak B (eds). Bone tumors. St Louis: Mosby, 1998: 598.

19. Averill RM, Smith RJ, Campbell CJ. Giant cell tumors of the bo- 
nes of the hand. J Hand Surg A, 1980; 5: 39-50.

20. Snarkin NG, Mott MG, Roylance J. A unusual intraosseous lesion with fibroblastic, osteoclástica, osteoblastic, aneurismal and fibromyxoid elements: "solid" variant of aneurismal bone cyst. Cancer, 1983; 51: 2278-86.
21. Bertoni F, Bacchini P, Capanna $R$, Ruggieri $P$, Biagini R, Ferruzzi $A$, et al. Solid variant of aneurismal bone cyst. Cancer, 1993; 71: 729-34.

22. Oda Y, Tsuneyoshi M, Shinohara N. "Solid" variant of aneurysmal bone cyst (extragnatic giant cell reparative granuloma) in the axial skeleton and long bones: a study of its morphologic spectrum and distinction from allied giant cell lesion. Cancer, 1992; 70: 2642-9.

23. Glass TA, Mills SE, Fechner RE, Dyer R, Martin W, Armstrong P. Giant-cell reparative granuloma of the hands and feet. Radiology, 1983; 149: 65-8. 